SILVA, E.C.; MIRANDA, J.R.P.; ALVARENGA, M.A.R. Concentração de nutrientes e produção do tomateiro podado e adensado em função do uso de fósforo, de gesso e de fontes de nitrogênio. Horticultura Brasileira, Brasília, v. 19, n. 1, p. 64-69, março 2001.

\title{
Concentração de nutrientes e produção do tomateiro podado e adensado em função do uso de fósforo, de gesso e de fontes de nitrogênio.
}

\author{
Ernani C. Silva ${ }^{1}$; José R. P. Miranda ${ }^{2}$; Marco A. R. Alvarenga ${ }^{3}$ \\ ${ }^{1}$ UFS-DEA, Cidade Universitária "Prof. José Aloísio de Campos", 49.100-000, São Cristóvão-SE- E-mail: clarsil@ bol.com.br; ${ }^{2}$ UFPB- \\ CSTR-Depto.Eng ${ }^{a}$. Florestal, Campus VII, 58.700-970, Patos-PB; ${ }^{3}$ UFLA-DAG, C. Postal 37, 37.200-000, Lavras-MG, E-mail: \\ marcoant@ufla.br
}

\section{RESUMO}

Este trabalho foi conduzido em Lavras-MG, em 1997, para estudar a absorção de nutrientes e a produção de tomateiro no sistema podado e adensado, sob diferentes doses de gesso, $\mathrm{P}_{2} \mathrm{O}_{5}$ e fontes de $\mathrm{N}$ e de $\mathrm{P}$, considerando também o sistema de produção convencional. Foram estudadas três doses de $\mathrm{P}_{2} \mathrm{O}_{5}(0,2 ; 0,4$ e $0,6 \mathrm{t} / \mathrm{ha})$ na forma de superfosfato triplo e quatro doses de gesso $(0,3 ; 0,6 ; 0,9$ e 1,2 $\mathrm{t} / \mathrm{ha}$ ), arranjadas como fatorial $3 \times 4$, no delineamento experimental de blocos casualizados, com quatro repetições. Foram incluídos quatro tratamentos adicionais abrangendo espaçamentos e poda e fontes de N e P. A produção comercial cresceu linearmente com as doses de $\mathrm{P}_{2} \mathrm{O}_{5}$ e decresceu com o uso de gesso. As maiores produções, ao limite de 149,2 t/ha, foram obtidas com plantas podadas e adensadas. As menores produções, $91 \mathrm{t} / \mathrm{ha}$ (plantas podadas) e 63,2 t/ha (plantas não podadas), foram obtidas com o uso de $\mathrm{N}$ (sulfato de amônio) e $\mathrm{P}$ (superfosfato simples). O teor de $\mathrm{P}$ nas folhas decresceu linearmente com o aumento das doses de gesso e variou de 3,0 a $1,7 \mathrm{~g} / \mathrm{kg}$ com o menor teor observado nos tratamentos adicionais $\mathrm{N}$ (sulfato de amônio) e P (superfosfato simples). O teor de Mg nas folhas foi em média $4,7 \mathrm{~g} / \mathrm{kg}$ sem diferenças significativas considerando os tratamentos com gesso e $\mathrm{P}_{2} \mathrm{O}_{5}$, mas foram encontrados teores de $\mathrm{Mg}$ em torno de 3,0 g/kg no tratamento adicional $\mathrm{N}$ (sulfato de amônio) e P (superfosfato simples), estatisticamente diferente dos demais tratamentos. O teor de $\mathrm{Cu}(79,4 \mathrm{mg} / \mathrm{kg})$ observado no tratamento adicional onde foi usada uréia como fonte de $\mathrm{N}$ e superfosfato triplo como fonte de $\mathrm{P}$, foi estatisticamente diferente de $120,6 \mathrm{~g} / \mathrm{kg}$, encontrado no outro tratamento adicional. O teor de $\mathrm{Cu}$ elevou-se também com o aumento das doses de gesso. Conclui-se que o uso excessivo de fertilizantes cujas fórmulas contenham $\mathrm{S}$ pode inibir a absorção de $\mathrm{P}$, assumindo maiores proporções nos plantios adensados. A redução do número de frutos por planta através da poda, quando associada com maior densidade de plantio, pode resultar em ganho altamente significativo de produtividade.

Palavras-chave: Lycopersicon esculentum Mill, fósforo, adubação fosfatada, gessagem, sistemas de produção.

\begin{abstract}
Yield and nutrient concentration of tomato plants pruned and grown under high planting density according to phosphorus,
\end{abstract} gypsum and nitrogen sources.

This research was carried out at Lavras, Minas Gerais State (Brazil) in 1997. The objective was to study nutrient absorption by tomato plants pruned and grown under high planting density over different gypsum, $\mathrm{P}_{2} \mathrm{O}_{5}$ rates and different $\mathrm{N}$ and $\mathrm{P}$ sources. The yield was also analyzed, considering conventional planting systems. The experimental design was of complete randomized blocks with four replications in a factorial scheme $3 \times 4$ with three rates of $\mathrm{P}_{2} \mathrm{O}_{5}$ triple superphosphate $(0.2,0.4$, and $0.6 \mathrm{t} / \mathrm{ha})$ and four rates of gypsum $(0.3,0.6,0.9$ and 1.2 $\mathrm{t} / \mathrm{ha}$ ). Four additional treatments were included about planting system and soil fertilization. A linear increase was observed on the commercial tomato yield with the increasing of $\mathrm{P}_{2} \mathrm{O}_{5}$ rates whereas linear decreasing was observed with the increasing of gypsum rates. The production up to $149.2 \mathrm{t} /$ ha was obtained with plants pruned and grown under high planting density. The lower production, $91 \mathrm{t} / \mathrm{ha}$ (pruned plants) and $63.2 \mathrm{t} / \mathrm{ha}$ (not pruned plants), was obtained using ammonium sulfate (N source) and single superphosphate (P source). Leaf P contents, with values around 3.0 a $1.7 \mathrm{~g} / \mathrm{kg}$, decreased with the increase of gypsum rates. The lower leaf $\mathrm{P}$ content was observed in the additional treatment with ammonium sulfate and single superphosphate. The mean value of magnesium contents was $4.7 \mathrm{~g} / \mathrm{kg}$ without statistically significant differences considering gypsum and $\mathrm{P}_{2} \mathrm{O}_{5}$ treatments. Otherwise values of magnesium contents around $3.0 \mathrm{~g} / \mathrm{kg}$ were found under additional treatments, statistically different when compared to the treatments above mentioned. The observed $\mathrm{Cu}$ values of $79.4 \mathrm{mg} / \mathrm{kg}$ in another additional treatment using urea as $\mathrm{N}$ source, and triple superphosphate as P source was statistically different with values of $120.6 \mathrm{~g} / \mathrm{kg}$, observed in the first additional treatment. Leaf $\mathrm{Cu}$ contents also increased with the increase of gypsum rates. Its was concluded that high levels of fertilizers with sulfur can inhibit P uptake mainly in high planting density. Reduction of number of fruits per plant by pruning associated with high planting density can increase the yield.

Keywords: Lycopersicon esculentum Mill, phosphorus and gypsum fertilizers, production system.

\section{(Aceito para publicação em 12 de dezembro de 2.000)}

$\mathrm{O}$ Brasil é o nono maior produtor mundial de tomate e o décimo primeiro em termos de área plantada (Agrianual, 1999). A produção em 1998 foi de 2.615 milhões de toneladas em uma área de 59.810 ha, colocando essa espécie como a hortaliça mais impor- tante no Brasil, incluindo os aspectos sócioeconômicos (Makishima,1991). Entretanto, a produtividade média de 43,7 t/ha é muito baixa, tendo em vista a potencialidade produtiva do tomateiro. Nos últimos anos, têm sido usadas técnicas e práticas mais sofisticadas, alia- das a sistemas de produção mais modernos e a cultivares híbridas de tomate mais produtivas, no sentido de otimizar o potencial produtivo dessa cultura. A redução do número de hastes por planta e a poda apical para um número definido de cachos nas hastes são práticas 
alternativas de produção de tomates para consumo ao natural de modo a obteremse frutos com maior valor comercial (Oliveira et al., 1996; Silva et al., 1997; Camargos, 1998). A desbrota ou remoção de brotos axilares do tomateiro de crescimento determinado induz efeito semelhante ao observado em tomateiros de crescimento indeterminado, possibilitando maior percentagem de frutos graúdos, número e massa média de frutos produzidos precocemente (SilvaJúnior et al., 1992).

A quantidade de nutrientes absorvidos pela planta de tomate e o seu particionamento, geralmente associados ao crescimento da planta, depende de fatores bióticos e abióticos, dentre eles a prática da poda (Pelúzio, 1991), sistema de plantio (Fontes \& Fontes, 1991) e fontes e doses de nutrientes (Fontes \& Fontes, 1992). O uso do gesso na cultura de amendoim como fornecedor de $\mathrm{Ca}$ e $\mathrm{S}$ tem dado bons resultados (Quaggio et al., 1982) assim como em soja (Mascarenhas et al., 1976) e cenoura (Castellane et al., 1983). Entretanto, apesar da importância do gesso como fonte de nutrientes, sua utilização pode prejudicar a nutrição e a produção das plantas quando empregado em doses que elevem excessivamente a disponibilidade de Ca e S (Martinez et al., 1983).

Os objetivos do trabalho foram estudar o efeito de doses de gesso e doses de $\mathrm{P}_{2} \mathrm{O}_{5}$ e diferentes fontes de $\mathrm{N}$ e de $\mathrm{P}$ na absorção de nutrientes pelo tomateiro podado e adensado e na produção do tomateiro em dois sistemas de produção, convencional e adensado.

\section{MATERIAL E MÉTODOS}

O trabalho foi conduzido no campo experimental da UFLA, em Lavras (MG), durante o ano de 1997, utilizando-se tomateiro do grupo Santa Cruz, cv. Santa Clara. O solo é do tipo Latossolo Vermelho Escuro distrófico (Led) com as seguintes características: $\mathrm{pH}$ em água $=4,9 ; \mathrm{P}=6 \mathrm{mg} / \mathrm{dm}^{3} ; \mathrm{K}=$ $63 \mathrm{mmol}_{\mathrm{c}} / \mathrm{dm}^{3} ; \mathrm{S}=37 \mathrm{mg} / \mathrm{dm}^{3} ; \mathrm{Ca}=2,5$ $\mathrm{mmol} / \mathrm{dm}^{3} ; \mathrm{Mg}=0,3 \mathrm{mmol} / \mathrm{dm}^{3} ; \mathrm{Cu}=$ $4,3 \mathrm{mg} / \mathrm{dm}^{3} ; \mathrm{Fe}=43,5 \mathrm{mg} / \mathrm{dm}^{3} ; \mathrm{Mn}=$ $45,0 \mathrm{mg} / \mathrm{dm}^{3} ; \mathrm{Zn}=1,8 \mathrm{mg} / \mathrm{dm}^{3} ; \mathrm{Al}=$ $0,1 \mathrm{mmol} / \mathrm{dm}^{3} ; \mathrm{V}=45 \%$; M.O. $=3,0$ $\mathrm{dag} / \mathrm{kg}$; $\operatorname{areia}=22 \mathrm{~g} / \mathrm{kg} ;$ limo $=24 \mathrm{~g} / \mathrm{kg}$; $\operatorname{argila}=54 \mathrm{~g} / \mathrm{kg}$.
Utilizou-se o extrator Mehlich 1 para $\mathrm{P}, \mathrm{K}, \mathrm{Zn}, \mathrm{Mn}, \mathrm{Fe}$ e $\mathrm{Cu}$, sendo o P determinado pelo método colorimétrico; $\mathrm{K}$ por fotometria de chamas e os demais nutrientes por espectrofotometria de absorção atômica. O B foi extraído com água quente e determinado por processo colorimétrico. Para $\mathrm{Ca}, \mathrm{Mg}$ e $\mathrm{Al}$ utilizou-se extrator $\mathrm{KCl} 1 \mathrm{M}$ com a determinação de $\mathrm{Ca}$ e $\mathrm{Mg}$ feita por titulação com EDTA e Al por titulação com $\mathrm{NaOH}$. O S foi determinado por extração com fosfato monocálcico em ácido acético (método Hoeft).

A propagação do tomateiro foi em bandejas de isopor, com 128 células, sob estufa de cobertura de polietileno utilizando-se substrato comercial à base de vermiculita expandida e resíduo orgânico. O transplante foi efetuado quando as mudas apresentavam quatro folhas definitivas. No campo, o arranjo das plantas foi em fileira dupla $(0,8 \mathrm{~m}$ entre fileiras duplas x $0,4 \mathrm{~m}$ entre fileiras simples x 0,4 m entre plantas) com densidade de 41.500 plantas/ha, sendo uma planta por cova. As plantas foram conduzidas com uma haste e podadas após o quarto ramo floral, imediatamente acima da terceira folha. Também fezse uso do cultivo convencional em espaçamento $1,0 \mathrm{~m}$ x 0,50 m, densidade de 20.000 plantas/ha, onde as plantas foram mantidas com uma haste em livre crescimento. Tratos culturais e fitossanitários foram feitos de acordo com o recomendado para a cultura do tomateiro (Barbosa \& França, 1980; Churata-Masca, 1980; Maffia et al., 1980; Manzan, 1980). Os tratamentos em estudo foram três doses de $\mathrm{P}_{2} \mathrm{O}_{5}$ na forma de superfosfato triplo $(0,2 ; 0,4 \mathrm{e}$ $0,6 \mathrm{t} / \mathrm{ha})$ e quatro doses de gesso $(0,3$; $0,6 ; 0,9$ e $1,2 \mathrm{t} / \mathrm{ha})$, mais quatro tratamentos adicionais envolvendo fontes de nitrogênio, fontes de fósforo e formas de condução das plantas, arranjados no delineamento experimental em blocos casualizados, em esquema fatorial $3 \times 4$ +4 , com quatro repetições. Os tratamentos envolvendo adubações foram propostos com base nas recomendações para adubação do tomateiro (CFSEMG, 1989). O gesso apresentava $32,6 \%$ de $\mathrm{CaO}$ e $18,6 \%$ de $\mathrm{S}$. Todas as parcelas receberam, por ocasião do transplantio, $180 \mathrm{~kg} / \mathrm{ha}$ de $\mathrm{K}_{2} \mathrm{O}$, na forma de $\mathrm{KCl}$. Os tratamentos fatoriais receberam $120 \mathrm{~kg}$ / ha de $\mathrm{N}$, na forma de uréia e fósforo na forma de superfosfato triplo. Os tratamentos adicionais não receberam gesso e constaram de: a) $120 \mathrm{~kg} / \mathrm{ha}$ de $\mathrm{N}$ na forma de uréia, $400 \mathrm{~kg} / \mathrm{ha}$ de $\mathrm{P}_{2} \mathrm{O}_{5}$ na forma de superfosfato triplo, com plantas podadas e cultivadas em fileira dupla $(0,40 \times 0,40 \times 0,8 \mathrm{~m}) ; \mathrm{b}) 120 \mathrm{~kg} / \mathrm{ha}$ de $\mathrm{N}$ na forma de sulfato de amônio e $400 \mathrm{~kg} / \mathrm{ha}$ de $\mathrm{P}_{2} \mathrm{O}_{5}$ na forma de superfosfato simples, com plantas podadas e cultivadas em fileiras duplas $(0,40$ x $0,40 \times 0,8 \mathrm{~m}) ; \mathrm{c}$ ) convencional - 120 $\mathrm{kg} / \mathrm{ha}$ de $\mathrm{N}$ na forma de sulfato de amônio e $400 \mathrm{~kg} / \mathrm{ha}$ de $\mathrm{P}_{2} \mathrm{O}_{5}$ na forma de superfosfato simples, com plantas cultivadas em fileiras simples $(1,0 \times 0,5 \mathrm{~m})$ sem poda e d) $120 \mathrm{~kg} / \mathrm{ha}$ de $\mathrm{N}$ na forma de uréia com plantas podadas e cultivadas em fileiras duplas $(0,40 \times 0,40 \times 0,8$ $\mathrm{m})$, omitindo-se a adubação fosfatada. Assim, cada bloco ficou com 16 parcelas, sendo doze do fatorial e quatro dos tratamentos adicionais. As parcelas foram formadas por doze plantas úteis no tratamento convencional e por oito plantas úteis nos demais tratamentos.

A adubação em cobertura consistiu da aplicação total de $120 \mathrm{~kg} / \mathrm{ha}$ de $\mathrm{N}$ na forma de uréia parcelados em três aplicações iguais, aos 20, 40 e 60 dias após o transplantio nos tratamentos que receberam doses de gesso e doses de $\mathrm{P}_{2} \mathrm{O}_{5}$ e nos dois tratamentos adicionais que receberam $\mathrm{N}$ na forma de uréia. Nos outros dois tratamentos adicionais que receberam sulfato de amônio no transplantio, a adubação em cobertura foi feita com sulfato de amônio nas mesmas épocas e datas descritas. Todas as parcelas receberam um total de 120 $\mathrm{kg} / \mathrm{ha}$ de $\mathrm{K}_{2} \mathrm{O}$ em cobertura, parcelados e aplicados da mesma forma que o nitrogênio. As adubações foram localizadas nos sulcos de plantio.

Os teores de $\mathrm{P}, \mathrm{K}, \mathrm{Ca}, \mathrm{Mg}, \mathrm{S}, \mathrm{Cu}$, $\mathrm{Fe}, \mathrm{Mn}$ e $\mathrm{Zn}$ nas folhas do tomateiro foram analisados segundo delineamento experimental $3 \times 4+2$, considerando os dois tratamentos adicionais onde as plantas foram podadas e receberam $\mathrm{N} \mathrm{e}$ $\mathrm{P}_{2} \mathrm{O}_{5}$, com e sem enxofre na fórmula. As análises foram feitas em amostras das terceiras folhas a partir da extremidade, aos 100 dias após o transplantio. Os teores de K, P, S, Ca e Mg foram determinados no extrato nítrico-perclórico, utilizando-se método colorimétrico para o 


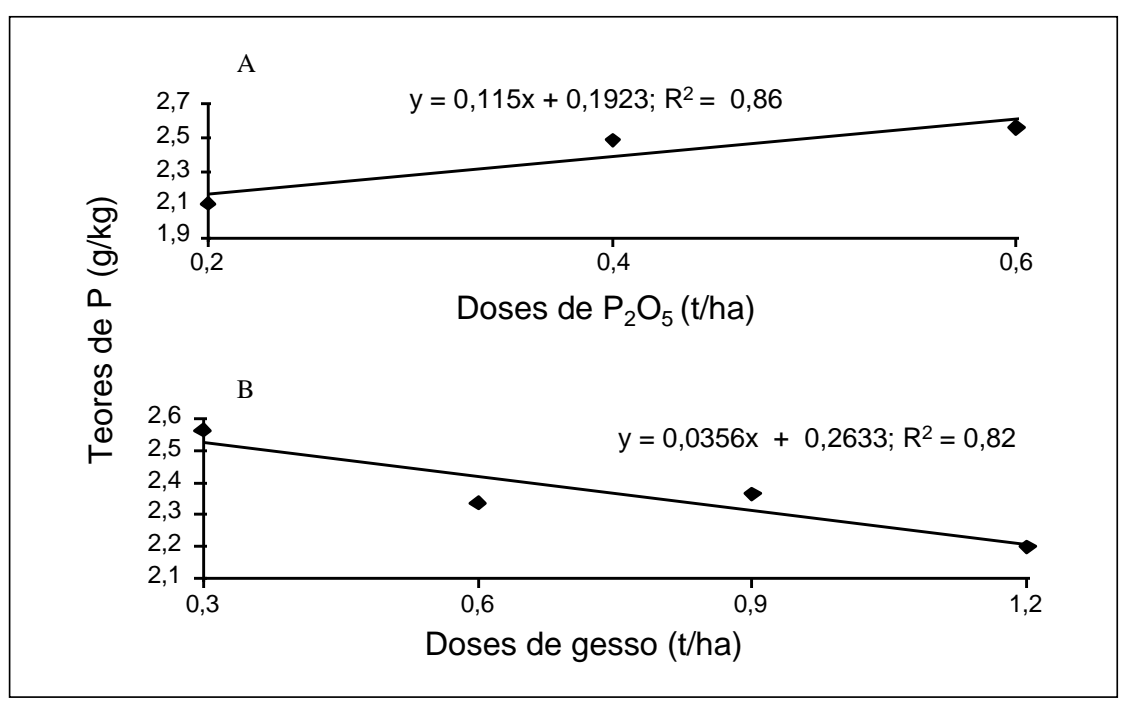

Figura 1. Teor de $\mathrm{P}$ na folha do tomateiro em função de doses de $\mathrm{P}_{2} \mathrm{O}_{5}(\mathrm{~A})$ e doses de gesso (B). Lavras, UFLA, 1997.

fósforo; fotometria de chamas para o potássio; turbidimetria para o enxofre e espectrofotometria de absorção atômica para os demais nutrientes (Malavolta et al.,1989). As colheitas iniciaram-se aos 110 dias após o semeio, quando os frutos apresentavam coloração avermelhada. Nessa época, avaliaramse produção comercial, caracterizada por frutos livres de injúrias quer provocadas por pragas ou doenças, independente do tamanho; produção de frutos graúdos (frutos $>52 \mathrm{~mm}$ de diâmetro); massa média de fruto e produção de frutos por planta. Para essas análises foram incluídos todos os tratamentos em esquema fatorial $3 \times 4+4$.

Foi realizada análise estatística específica para o fatorial $3 \times 4$, considerando todas as características analisadas; uma análise específica para os dois tratamentos adicionais do esquema fatorial $3 \times 4$ +2 , considerando apenas os teores de nutrientes nas folhas e uma análise específica para os quatro tratamentos adicionais, considerando todas as características avaliadas. Resíduos comuns foram obtidos e usados posteriormente para a análise de variância conjunta, empregando-se o teste F, ao nível de $5 \%$.

\section{RESULTADOS E DISCUSSÃO}

O teor de fósforo nas folhas dos tomateiros aumentou linearmente à medida que aumentaram as doses de $\mathrm{P}_{2} \mathrm{O}_{5}$, indicando não suficiência das doses aplicadas e o contrário aconteceu com a aplicação de gesso (Figura 1). A resposta positiva à aplicação de $\mathrm{P}_{2} \mathrm{O}_{5}$, em relação ao teor de $\mathrm{P}$ nas folhas do tomateiro, pode estar relacionada com a grande densidade de plantio. Por outro lado, o efeito depressivo do gesso sobre a absorção do fósforo, provavelmente, seja conseqüência do aumento da disponibilidade do ânion sulfato no solo, competindo com o fosfato pelos mesmos sítios de absorção ou ainda pode ter provocado redução na translocação do $\mathrm{P}$ para a parte aérea, devido à habilidade de o tomateiro acumular sulfato em suas raízes (Martinez et al., 1983). Os teores de $\mathrm{P}$ nas folhas do tomateiro variaram de 1,7 a $3,0 \mathrm{~g} / \mathrm{kg}$ o que pode indicar uma provável carência do nutriente, uma vez que Nishimoto et al. (1977) observaram que para o tomateiro atingir $95 \%$ do seu rendimento máximo, os teores de $\mathrm{P}$ nas folhas variaram de 3,0 a 5,0 g/kg. É importante observar que o menor teor de fósforo encontrado $(1,7 \mathrm{~g} / \mathrm{kg})$, significativamente inferior ao de todos os outros tratamentos, correspondeu ao tratamento adicional onde as fontes de $\mathrm{N} \mathrm{e}$ de $\mathrm{P}_{2} \mathrm{O}_{5}$ forneceram o equivalente a 380 $\mathrm{kg} / \mathrm{ha}$ de enxofre, dose essa bem superior às aplicadas nos tratamentos fatoriais através do gesso.

Não foi observado efeito significativo dos tratamentos e das possíveis interações sobre o teor de $\mathrm{K}$, mostrando que as plantas acumularam esse nutriente independentemente dos tratamentos recebidos e a não ocorrência de antago- nismo entre Ca e K. Assim, os acréscimos no teor de Ca devido ao gesso e à adubação fosfatada não foram suficientes para provocar modificações significativas no padrão de absorção de K pelo tomateiro. Os teores de $\mathrm{K}$ encontrados no presente estudo variaram de 28 a 33 $\mathrm{g} / \mathrm{kg}$ e estão dentro da faixa adequada ao tomateiro (Furlani et al., 1978).

Para o teor de Ca nas folhas também não houve efeito significativo de nenhuma das fontes de variação e os teores encontrados variaram de 26 a $35 \mathrm{~g} / \mathrm{kg}$. Esta ausência de resposta deveu-se, provavelmente, à disponibilidade inicial do nutriente no solo, considerada alta. Em termos de nutrição, Takahashi (1989) observou que tomateiros com teores de $\mathrm{Ca}$ abaixo de $26 \mathrm{~g} / \mathrm{kg}$ produziram normalmente sem apresentar sintomas de podridão apical.

Em média o teor de $\mathrm{Mg}$ nas folhas foi de $4,7 \mathrm{~g} / \mathrm{kg}$. A análise isolada dos tratamentos que receberam doses de fósforo e gesso revelou não haver nenhum efeito significativo referente ao acúmulo de $\mathrm{Mg}$ nas folhas do tomateiro, o mesmo não acontecendo com os dois tratamentos adicionais e com a análise conjunta. As plantas podadas e adubadas com $\mathrm{N}$ (sulfato de amônio) e $\mathrm{P}_{2} \mathrm{O}_{5}$ (superfosfato simples) acumularam, significativamente, a menor quantidade de $\mathrm{Mg}(3,0 \mathrm{~g} / \mathrm{kg})$. Neste sentido, considerando-se que não foi fornecido $\mathrm{Mg}$ às plantas, algum fator deve ter contribuído para este resultado. Descarta-se a possibilidade de antagonismo entre $\mathrm{Ca}$ e Mg uma vez que, em três tratamentos que receberam doses de fósforo e gesso, foram fornecidas quantidades de $\mathrm{Ca}$ superiores ao tratamento em questão e, mesmo assim, as plantas apresentaram teores mais elevados de $\mathrm{Mg}$. Desta forma, possivelmente, o S componente dos fertilizantes ( $\mathrm{N}$-sulfato de amônio e $\mathrm{P}_{2} \mathrm{O}_{5}$ - superfosfato simples) tenha influenciado na absorção de Mg. Diante dos prováveis acréscimos na disponibilidade de sulfato e do provável acúmulo nas raízes, a absorção de $\mathrm{Ca}$ pode ter sido favorecida pela formação do par iônico $\mathrm{CaSO}_{4}$, em detrimento do Mg. Entretanto, os teores de $\mathrm{Mg}$ encontrados neste trabalho $(0,47 \mathrm{~g} / \mathrm{kg})$ podem ser considerados adequados para o tomateiro (Furlani et al., 1978). 
O acúmulo de S não foi influenciado significativamente pelos tratamentos e os teores encontrados nas folhas de tomateiro neste trabalho, variando de 4,0 a $5,0 \mathrm{~g} / \mathrm{kg}$, estão dentro dos limites de exigências do tomateiro (Takahashi, 1989). Os resultados parecem indicar que a disponibilidade inicial de $\mathrm{S}$ no solo atendeu às exigências das plantas, não havendo portanto, resposta dos tratamentos onde foram aplicadas doses de gesso. Segundo Castellane et al. (1983), aplicações de 15 - $50 \mathrm{~kg} / \mathrm{ha}$ de $\mathrm{S}$, que correspondem a 100 - $300 \mathrm{~kg} / \mathrm{ha}$ de gesso, são suficientes para atender às necessidades da maioria das culturas.

Houve efeito significativo da interação fósforo $\mathrm{x}$ gesso e dos tratamentos adicionais sobre os teores foliares de $\mathrm{Cu}$. Considerando apenas os tratamentos adicionais, constatou-se que o teor de $\mathrm{Cu}$ foi significativamente superior $(120,6 \mathrm{mg} / \mathrm{kg})$ no tratamento cujas plantas foram podadas e adubadas com sulfato de amônio e superfosfato simples, enquanto foi de 79,4 $\mathrm{mg} / \mathrm{kg}$ no tratamento cujas plantas receberam uréia e superfosfato triplo. Estes dados sugerem um possível efeito do ânion sulfato no processo de absorção e/ou translocação do $\mathrm{Cu}$. Por outro lado, os dados oriundos da interação fósforo $x$ gesso (Figura 2) não apresentaram consistência de modo a indicar ou não um possível antagonismo entre $\mathrm{P}$ e $\mathrm{Cu}$. À exceção da dose de 0,2 t/ha de $\mathrm{P}_{2} \mathrm{O}_{5}$, os teores de $\mathrm{Cu}$ na folha do tomateiro aumentaram linearmente com as doses crescentes de gesso. Não se encontrou na literatura consultada dados que confirmem ou não o efeito do gesso sobre a absorção de $\mathrm{Cu}$. É importante salientar que aos 100 dias após o transplantio, foram detectados sintomas de toxicidade de $\mathrm{Cu}$ nas plantas do tomateiro, confirmando a excessiva absorção deste nutriente, já que o normal situa-se entre 8 e $15 \mathrm{mg} / \mathrm{kg}$ (Bataglia,1988).

Os teores de $\mathrm{Fe}$ e Zn também não foram influenciados significativamente pelos tratamentos. Para Fe os teores variaram de 221 a $310 \mathrm{mg} / \mathrm{kg}$ e estão na faixa de suficiência para o tomateiro que compreende intervalo entre 40 - $400 \mathrm{mg}$ / kg (Bataglia, 1988). Quanto ao Zn os teores variaram de 21,4 a $29,3 \mathrm{mg} / \mathrm{kg}$, situando-se abaixo da faixa adequada para o tomateiro que é de 60 e $70 \mathrm{mg} / \mathrm{kg}$ (Bataglia, 1988), embora não tenha sido observado sintoma de deficiência do nutriente nas plantas. Esta baixa absorção

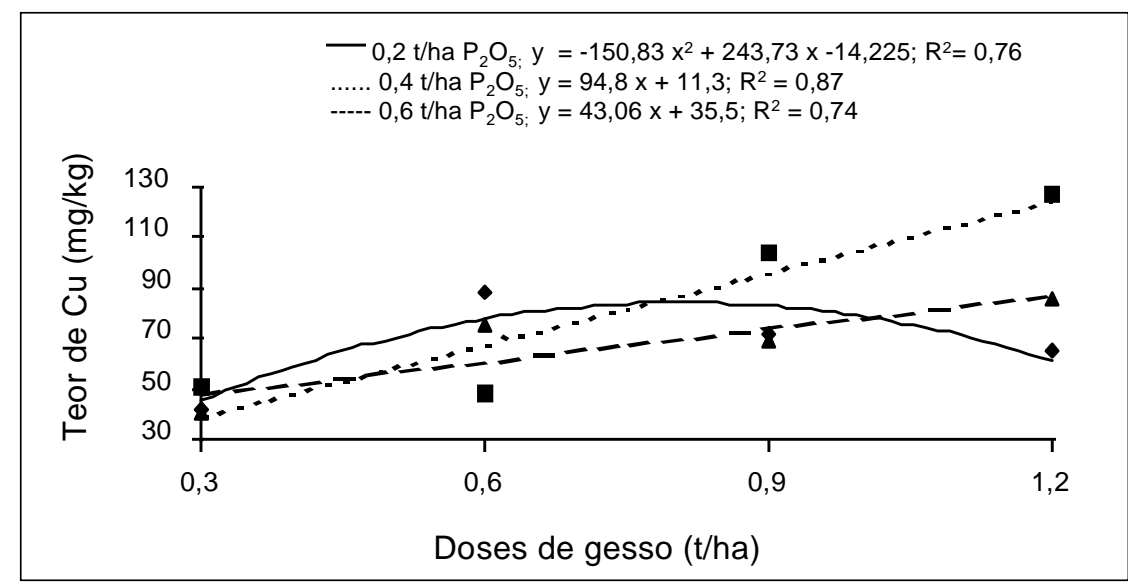

Figura 2. Teor de Cu na folha do tomateiro em função de doses de gesso. Lavras, UFLA, 1997.

de $\mathrm{Zn}$ pode estar relacionada com uma possível interação entre $\mathrm{P}$ e $\mathrm{Zn}$ durante os processos de absorção e translocação e do efeito do Ca sobre a absorção do referido nutriente, pois intensas adubações fosfatadas podem induzir deficiência de $\mathrm{Zn}$ em plantas cultivadas em solos com baixa disponibilidade deste nutriente (Loneragan et al., 1982).

Não houve efeito significativo dos tratamentos que receberam doses de gesso e doses de $\mathrm{P}_{2} \mathrm{O}_{5}$ no teor de $\mathrm{Mn}$ nas folhas do tomateiro registrando-se diferenças significativas apenas entre os tratamentos com $\mathrm{N}$ (uréia e amônia) e $\mathrm{P}_{2} \mathrm{O}_{5}$. (superfosfato simples e superfosfato triplo). Desta forma, observou-se que os teores de Mn detectados em plantas submetidas à poda e adubadas com sulfato de amônio e superfosfato simples foram significativamente inferiores aos observados nas plantas submetidas à adubação com uréia e superfosfato triplo. Do ponto de vista nutricional, os teores encontrados (253 a $384 \mathrm{mg} / \mathrm{kg}$ ) não assumem importância uma vez que estão próximo do limite máximo $(400 \mathrm{mg} / \mathrm{kg})$ definido por Bataglia (1988).

A produção comercial cresceu linearmente com as doses de $\mathrm{P}_{2} \mathrm{O}_{5}$ e decresceu com o uso de gesso (Figura 3). As menores produções, $91 \mathrm{t} / \mathrm{ha}$ (plantas podadas) e 63,2 t/ha (plantas não podadas), foram obtidas com o uso de $\mathrm{N}$ na forma de sulfato de amônio e P na forma de superfosfato simples além de 58,4 $\mathrm{t} /$ ha no tratamento com plantas podadas cuja fonte de $\mathrm{N}$ foi uréia, omitindo-se $\mathrm{P}$. Quanto ao efeito do gesso, possivelmente o S-orgânico do solo, acrescido do S fornecido pelo gesso, superfosfato simples e sulfato de amônio tenham atingi- do teores capazes de desequilibrar a relação S/N do solo e prejudicar o rendimento da cultura. Considerando plantas podadas, a produtividade significativamente inferior em relação às maiores observadas nos tratamentos com doses de gesso e $\mathrm{P}$, pode também ser conseqüência do efeito depressivo do $\mathrm{S}$ proveniente do sulfato de amônio e do superfosfato simples. Para as plantas não podadas, além do efeito depressivo de $\mathrm{S}$, deve ser também considerado o espaçamento de $1,0 \times 0,50 \mathrm{~m}$ com densidade de plantio de 20.000 plantas/ha, portanto, inferior ao dos demais tratamentos. A omissão de $\mathrm{P}$, embora possa ter reduzido o efeito depressivo do $\mathrm{S}$, provavelmente tenha contribuído para a baixa produtividade.

As diferenças de produtividade entre o tratamento onde as plantas não foram podadas e os demais tratamentos cuja maior produtividade atingiu 149,2 t/ha, podem ser também atribuídas ao emprego conjunto da poda e do aumento da densidade populacional (41.500 plantas/ha). Embora possa haver efeito depressivo no peso médio do fruto em função de alta densidade de plantio (Camargos, 1998) refletindo em menor produtividade comercial, este efeito pode ser invertido através da poda apical e adubação adequada (Cochshull \& Ho, 1995; Silva et al., 1997).

Com base nos dados disponíveis na literatura consultada, o rendimento médio do tomateiro no Brasil é de 43,7 t/ ha (Agrianual, 1999) e considerando a dose de $400 \mathrm{~kg} / \mathrm{ha}$ de $\mathrm{P}_{2} \mathrm{O}_{5}$ como adequada para solos deficientes em P (Comissão..., 1989), a produção alcançada 


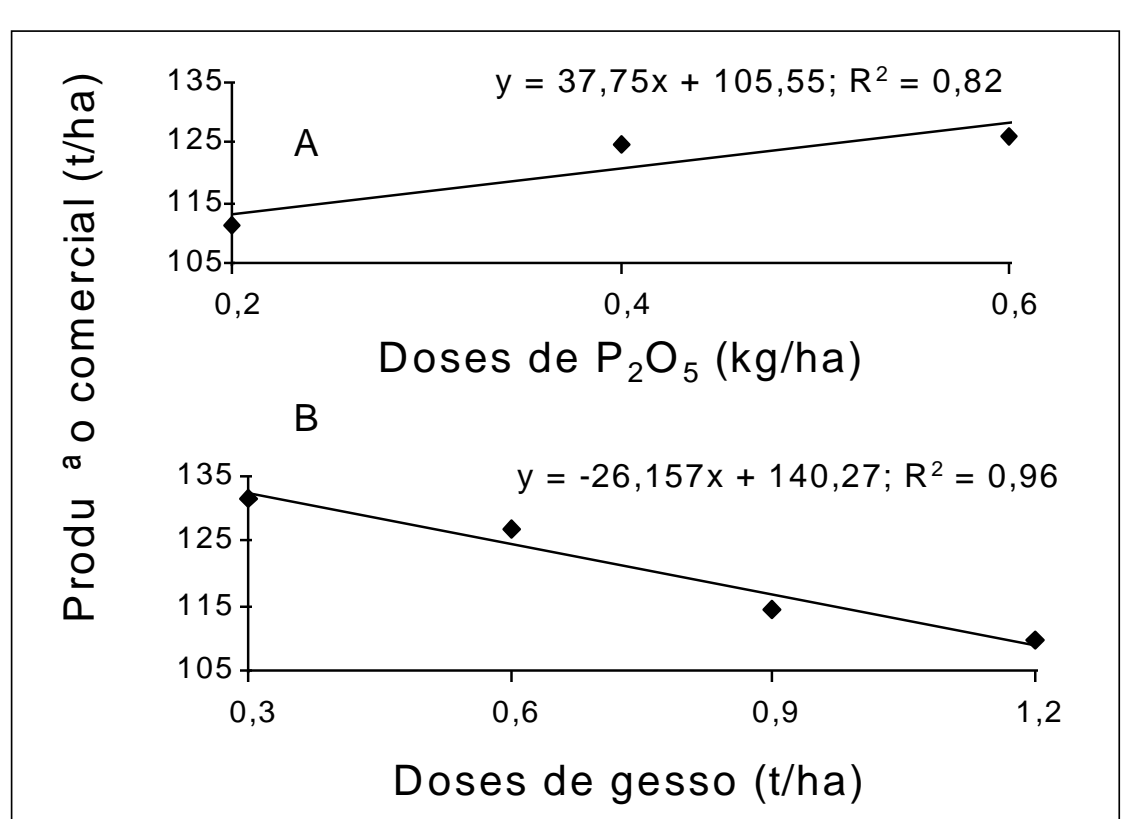

Figura 3. Produção comercial do tomateiro em função de doses de $\mathrm{P}_{2} \mathrm{O}_{5}(\mathrm{~A})$ e doses de gesso (B). Lavras, UFLA, 1997.

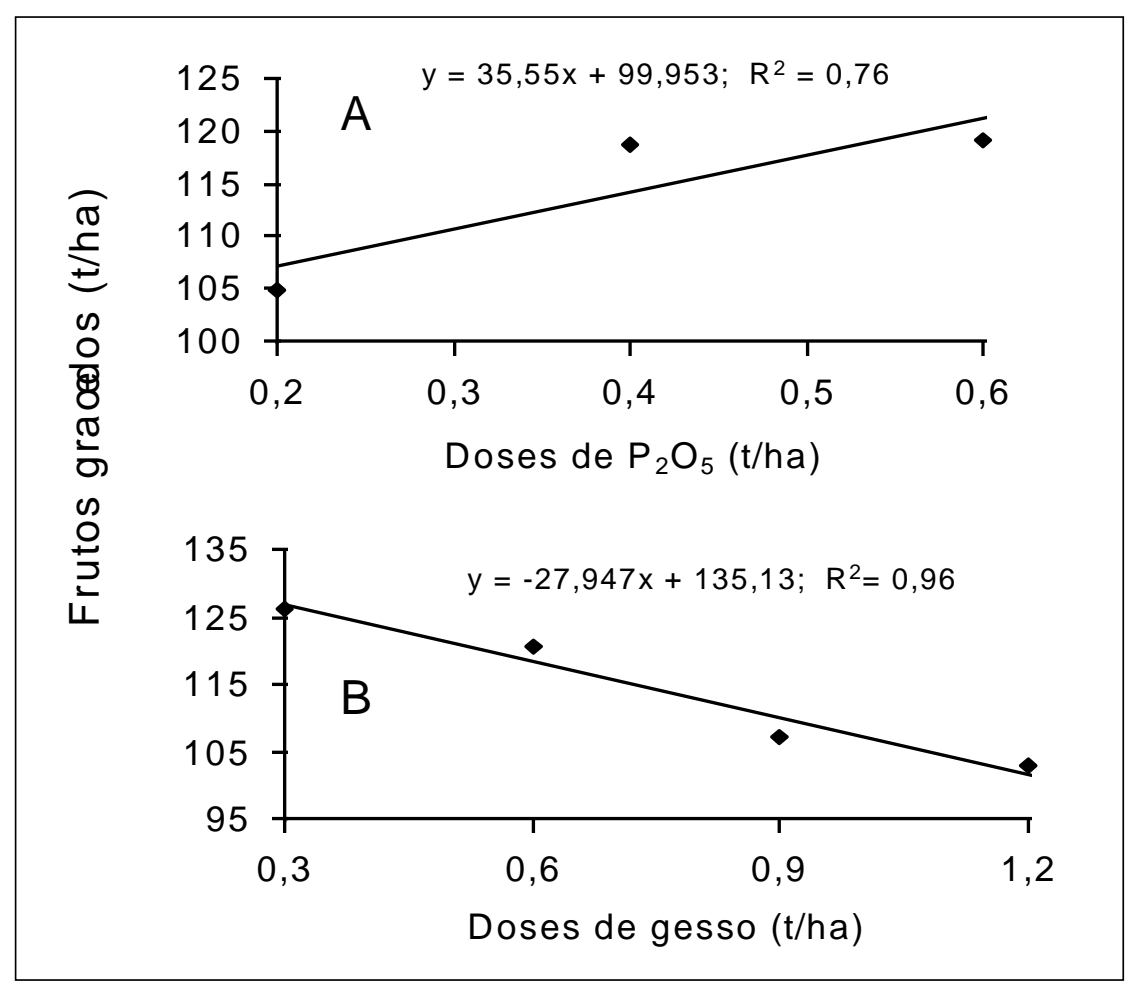

Figura 4. Produção de frutos graúdos de tomate em função de doses de $\mathrm{P}_{2} \mathrm{O}_{5}(\mathrm{~A})$ e doses de gesso (B). Lavras, UFLA, 1997.

(Figura 3) indica que a utilização de plantio adensado, associada à prática da poda, permitiu elevar a eficiência na utilização de fertilizante fosfatado. Os dados sugerem que o emprego de 400 $\mathrm{kg} / \mathrm{ha}$ de $\mathrm{P}_{2} \mathrm{O}_{5}$ foi vantajoso quando o rendimento foi comparado ao obtido com a dose menor embora tenha havido resposta linear à aplicação de fósforo sugerindo que produtividades mais altas podem ser conseguidas com aumento da dose de $\mathrm{P}_{2} \mathrm{O}_{5}$.

Tal como a produção comercial, a de frutos graúdos cresceu linearmente à medida que se aumentaram as doses de $\mathrm{P}_{2} \mathrm{O}_{5}$ e decresceu com as de gesso (Figura 4). A porcentagem média de frutos graúdos produzidos em relação à produção comercial foi de $94,56 \%$ entre os tratamentos que receberam doses de gesso e doses de $\mathrm{P}_{2} \mathrm{O}_{5}$ e o adicional que recebeu $\mathrm{N}$ (uréia), $400 \mathrm{~kg} / \mathrm{ha} \mathrm{P}_{2} \mathrm{O}_{5}$ (superfosfato triplo) e plantas podadas, não havendo diferenças estatísticas entre eles. Para os demais tratamentos adicionais, a produção média de frutos graúdos foi significativamente baixa com $86,09 \%$. Os resultados corroboram os efeitos positivos da poda e do fósforo na produtividade do tomateiro.

As massas médias de $104 \mathrm{~g}$ (N - sulfato de amônio, $\mathrm{P}_{2} \mathrm{O}_{5}$ - superfosfato simples, plantas podadas) e $107 \mathrm{~g}$ ( $\mathrm{N}$ - uréia, omissão de $\mathrm{P}_{2} \mathrm{O}_{5}$ e plantas podadas) foram iguais estatisticamente, mas diferiram daqueles outros doze tratamentos, cujas médias variaram de 110 a 142g, consideradas iguais estatisticamente. Independente dos tratamentos, essas médias situaramse abaixo do padrão de fruto Santa Clara que, em média, atinge $200 \mathrm{~g} /$ fruto (Nagai, 1985). A prática da poda per se seria suficiente para manter ou elevar as massas médias obtidas neste experimento (Cochshull \& Ho, 1995; Silva et al.,1997), entretanto, os efeitos negativos do gesso, sulfato de amônio e superfosfato simples provavelmente tenham superado os efeitos benéficos da poda, já que houve problemas na absorção de nutrientes indicando possível deficiência de $\mathrm{P}$ e Zn e excesso $\mathrm{Cu}$, embora os demais nutrientes estivessem aparentemente dentro dos níveis normais. Silva et al. (1997) cultivaram tomateiro Santa Clara podado acima do quarto ramo floral, adensado, utilizando como fonte de nutrientes $600 \mathrm{~kg} / \mathrm{ha}$ de $\mathrm{P}_{2} \mathrm{O}_{5}$ (superfosfato triplo), 100, 200, 400 e $800 \mathrm{~kg} /$ ha de $\mathrm{N}$ (nitrocálcio) e 200 , 400,800 e $1200 \mathrm{~kg} / \mathrm{ha}$ de $\mathrm{K}_{2} \mathrm{O}(\mathrm{KCl})$ e produziram frutos com massa média de 208,63 g.

A produção de frutos por planta teve influência significativa do gesso, fósforo e principalmente do sistema de condução das plantas. Foi verificado aumento linear com a adubação fosfatada, ao contrário do que aconteceu com a aplicação do gesso quando estes componentes foram analisados isoladamente (Figura 5). $\mathrm{O}$ efeito depressivo do gesso sobre a produção das plantas, possivelmente seja devido ao ânion sulfato concorrendo com os mesmos sítios de ab- 
sorção de fósforo. Por outro lado a produção das plantas verificada no tratamento adicional onde as mesmas não foram podadas atingiu média de $3,9 \mathrm{~kg} /$ planta e não diferiu estatisticamente da produção das plantas podadas que variou de 3,1 a $4,3 \mathrm{~kg} /$ planta. Neste caso a supressão do número de frutos ocasionada pela poda foi compensada pela maior produção de frutos graúdos, refletindo positivamente na produção por planta.

Diante dos resultados encontrados, conclui-se que o uso excessivo de fertilizantes cujas fórmulas contenham $\mathrm{S}$ pode inibir a absorção de $\mathrm{P}$, assumindo maiores proporções nos cultivos com alta densidade de plantio. No sistema de produção podado e adensado onde a redução do número de frutos/planta é associada com maior densidade de plantio, pode ocorrer aumento altamente significativo da produtividade.

\section{LITERATURA CITADA}

AGRIANUAL - Anuário da Agricultura Brasilei$r a$, FNP Consultoria e Comércio, São Paulo: Editora Argos. Comunicação. 521 p. 1999.

BARBOSA, S.; FRANÇA, F.H. As pragas do tomateiro e seu controle. Informe Agropecuário, Belo Horizonte, v. 6, n. 66, p. 37-40,1980.

BATAGLIA, O.C. Análise química de plantas para micronutrientes. In: SIMPÓSIO SOBRE MICRONUTRIENTES NA AGRICULTURA, 1988. Jaboticabal: UNESP, v. 2, p. 473-502, 1988.

CAMARGOS, M.I. Produção e qualidade de tomate longa vida em estufa, em função do espaçamento e do número de cachos por planta. Viçosa: UFV, 1998, 68 p. (Tese mestrado).

CHURATA-MASCA, M.G.C. Métodos de plantio na cultura do tomateiro. Informe Agropecuário, Belo Horizonte, v. 6, n. 66, p. 24-34, 1980.

CASTELLANE, S.R.P.L.; CASTELLANE, P.D.; VITTI, G.C.; BARBOSA, J.C.; CHURATAMASCA, M.G.C. Efeito da aplicação do gesso associado a fontes de $\mathrm{N}$ e $\mathrm{P}$ na cultura da cenoura (Daucus carota L.) In: CONGRESSO BRASILEIRO DE INICIAÇÃO CIENTÍFICA EM CIÊNCIAS AGRÁRIAS, 3, Florianópolis, 1983. Anais. Florianópolis: UFSC, 1983, p. 125.

COCKSHULL, K.L.; HO, L.C. Regulation of tomato fruit size by plant density and truss thinning. Journal of Horticultural Science, v. 70, n. 3, p. 395-407, 1995.

COMISSÃO DE FERTILIDADE DO SOLO DO ESTADODEMINAS GERAIS. Recomendações para o uso de corretivos e fertilizantes em Minas Gerais. 4ª aproximação. Lavras, 1989. 159 p.

FONTES, P.C.R.; FONTES, R.R. Absorção de P e desenvolvimento do tomateiro rasteiro plantado em fileiras simples e duplas. Horticultura Brasileira, Brasília, v. 9, n. 2, p. 77-79, 1991.

FONTES, P.C.R.; FONTES, R.R. Absorção de P e crescimento do tomateiro influenciado por fontes, níveis e posicionamento do fertilizante. Horticultura Brasileira, Brasília, v. 10, n. 1, p. 11-13, 1992.

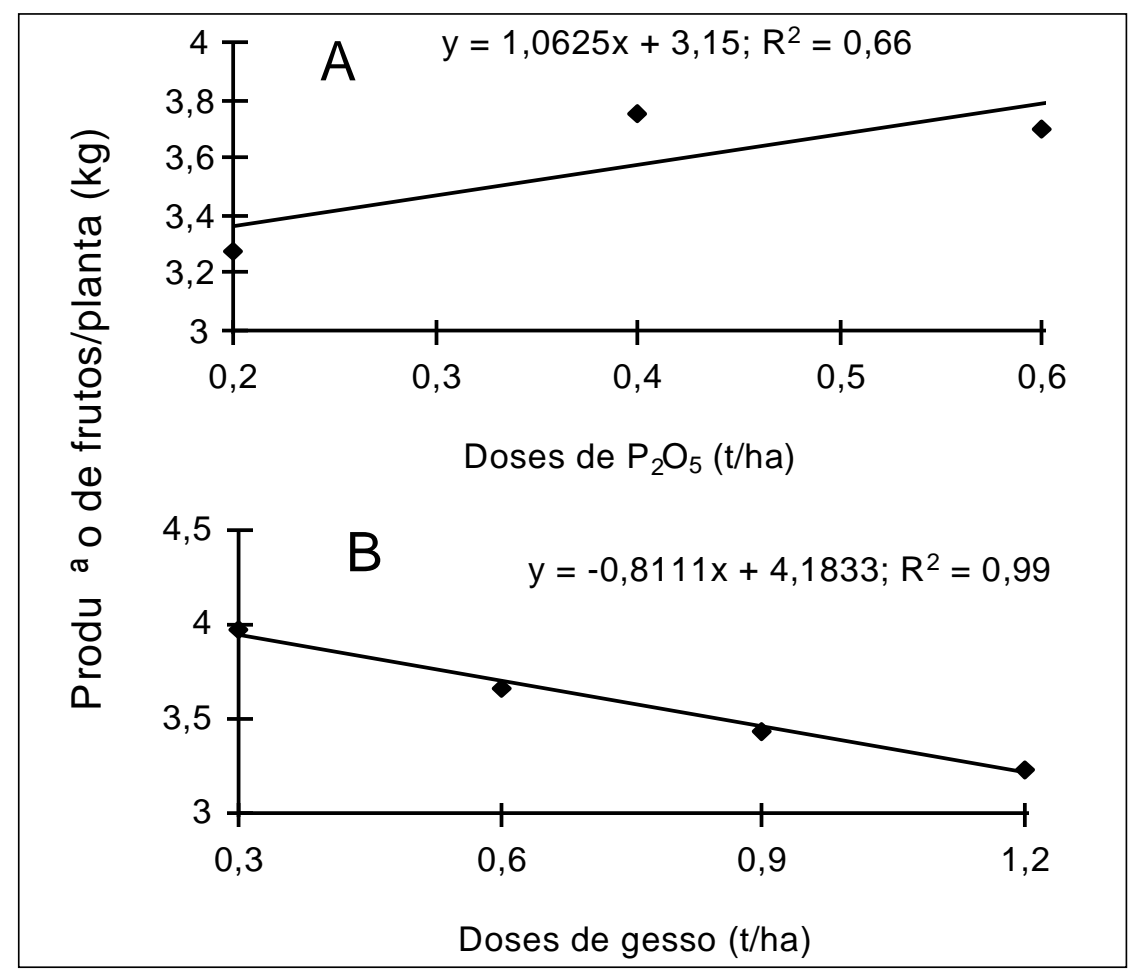

Figura 5. Produção de frutos por planta em função de doses de $\mathrm{P}_{2} \mathrm{O}_{5}(\mathrm{~A})$ e doses de gesso (B). Lavras, UFLA, 1997.

FURLANI, A.M.C.; FURLANI, P.R.; BATAGLIA, O.C.; HIROCE, R.; GALLO, J.R. Composição mineral de diversas hortaliças. Bragantia, Campinas, v. 37, n. 5, p. 3344, 1978.

LONERAGAN, J.F.; GRUNES, D.L.; WELCH, R.M.; ADUAYI, E.A.; TENGAH, A.; LAZAR, V.A.; CARY, E.E. Phosphorus accumulation and toxicity in relation to zinc supply. Soil Science Society of American Journal, v. 46, n. 2, p. 345-352, 1982.

MAFFIA, A.L.; MARTINS, M.C.P.; MATSUOKA, K. Doenças do tomateiro. Informe Agropecuário, Belo Horizonte, v. 6, n. 66, p. 42-60,1980.

MAKISHIMA, N. Situação atual da produção de tomate no Brasil. In: ENCONTRO NACIONAL DE PRODUÇÃO E ABASTECIMENTO DE TOMATE, 2, Jaboticabal, 1991. Anais. Jaboticabal: UNESP/FUNEP, p. 1-19. 1991.

MALAVOLTA, E.; VITTI, G.C.; OLIVEIRA, S.A. Avaliação do estado nutricional das plantas: princípios e aplicações. Piracicaba: Associação Brasileira para Pesquisa da Potassa e do Fosfato, 1989. 210 p.

MANZAN, R.J. Irrigação do tomateiro. Informe Agropecuário, Belo Horizonte, v. 6, n. 66, p. 20-21,1980.

MARTINEZ, V.; CERDA, A.; CARO, M.; FERNANDEZ, F.G. Desarrollo y composition mineral de las plantas de tomate (Lycopersicon esculentum, Mill.) en realacion con la concentracion de $\mathrm{SO}_{4}{ }^{=}$en el medio de raices. Anuals de Edofologia y Agrobiologia, v. 42, n. 7/8, p. 1255-1268, 1983.

MASCARENHAS, H.A.A.; BRAGA, N.R.; TISSELI FILHO, O; MIRANDA, M.A.C.; ROSTON, A.J. Calagem e adubação da soja. Campinas: IAC, 1976. 7 p. (Circular Técnica, 51).
NAGAI, H. IAC Santa Clara, nova variedade de tomate. Dirigente Rural, São Paulo, v. 24, n. 11, p. 52, 1985.

NISHIMOTO, R.K.; FOX, R.L.; PARVIN, P.E. Response of vegetable crops to phosphorus concentration in soil solution. Journal of the American Society for Horticultural Science, v. 102, n. 6, p. 705-709, 1977.

OLIVEIRA, V.R.; FONTES, P.C.R.; CAMPOS, J.P.; REIS, F.P. Qualidade no tomate afetada pelo número de ramos por planta e pela poda apical. Revista Ceres, Viçosa, v. 43, n. 247, p. 309-318, 1996.

PELÚZIO, J.M. Crescimento e partição de assimilados em tomateiro (Lycopersicon esculentum, Mill.) após a poda apical. Viçosa: UFV, 1991. 49 p. (Tese mestrado).

QUAGGIO, J.A.; DECHEN, A.R.; RAIJ, B. van. Efeito da aplicação de calcário e gesso sobre a produção de amendoim e lixiviação de bases no solo. Revista Brasileira de Ciência do Solo, Campinas, v. 6, n. 3, p. 188-194, 1982.

SILVA, E.C.; ALVARENGA, M.A.R.; CARVALHO, J.G. Produção e podridão apical do tomateiro (Lycopersicon esculentum Mill.) podado e adensado sob influência da adubação nitrogenada e potássica. Ciência e Agrotecnologia, Lavras, v. 21, n. 3, p. 324-333, 1997.

SILVA JÚNIOR, A.A.; MÜLLER, J.J.V.; PRANDO, H.F. Poda e alta densidade de plantio na cultura do tomate. Agropecuária Catarinense, Florianópolis, v. 5, n. 1, p. 5761, 1992.

TAKAHASHI, H.W. Relação Ca:Mg:Kno desenvolvimento, produção, composição mineral e distúrbios fisiológicos relacionados com o $\mathrm{Ca}$ em tomateiro (Lycopersicon esculentum, Mill.). Piracicaba: ESALQ, 1989. 167 p. (Tese doutorado). 